\title{
Jogo Educativo Ambiental - O desafio de Gaia
}

Recibido: 15 Fed 2016 - Revisado: 30 Abr 2016 Aceptado: 30 May 2016 - Publicado: 30 Jul 2016

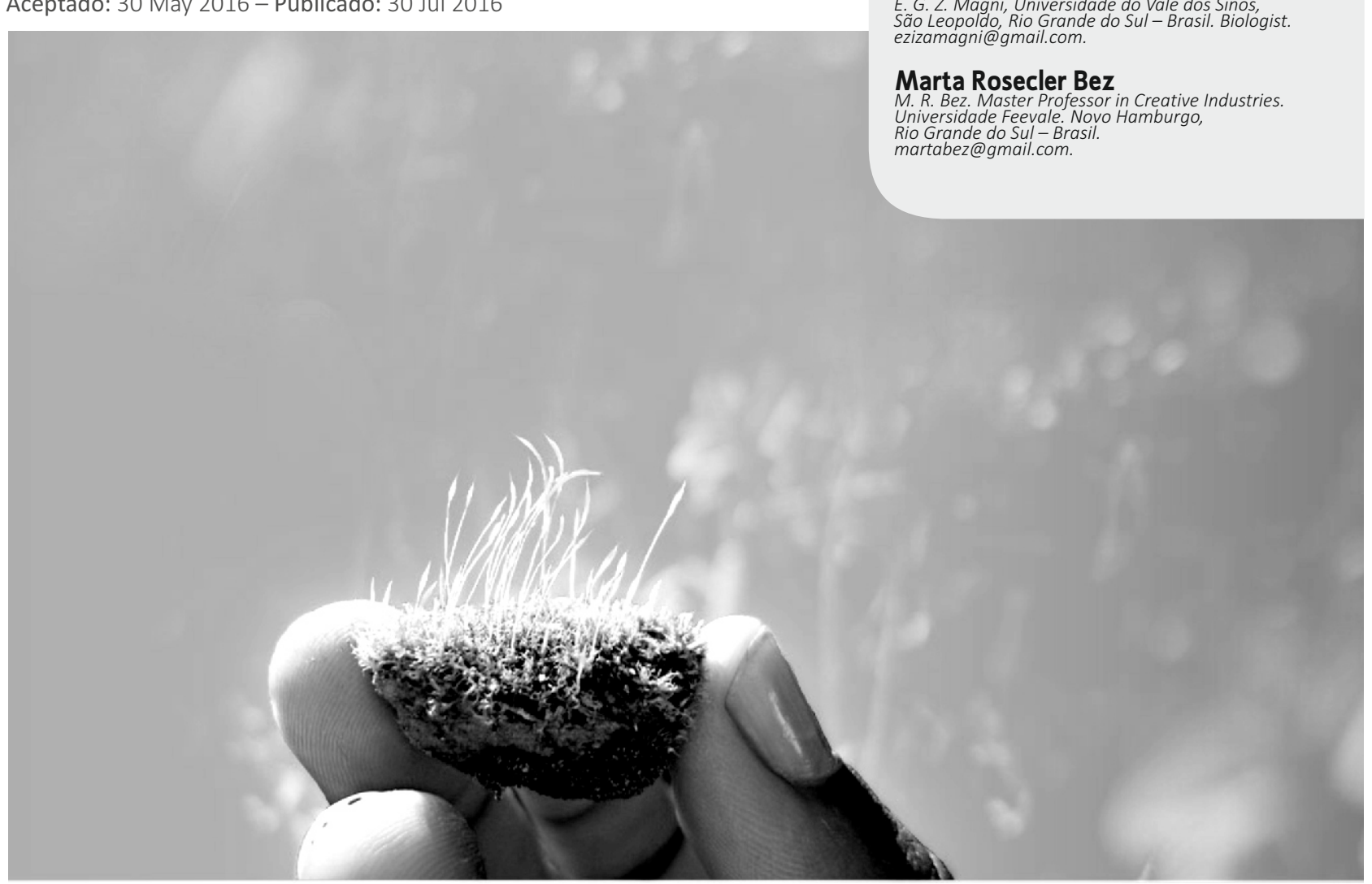

Resumo: Este artigo apresenta o experimento realizado com o ambiente de jogo Desafio de Gaia para uso em aulas de Educação Ambiental. O ambiente é formado por quatro temáticas: Água, Energia, Resíduos e Mobilidade. O jogo foi aplicado em uma turma de sexto ano de uma escola municipal e contou com a participação de 12 alunos. Foi realizado um pré-teste sobre o tema educação ambiental, antes do uso do jogo, seguido de um pós-teste. Os resultados apresentam evidências de aprendizado do tema tão somente com o uso do ambiente. Após o experimento, os alunos responderam a um teste de percepção sobre o uso do ambiente de jogo.

PALAVRAS-CHAVE: Tecnologia educacional, Atividades estudantis, Experimentos com estudantes

Abstract: This article presents the experiment conducted with the Gaia Challenge game environment for use in environmental education classes. The environment consists of four themes: Water, Energy, Waste and Mobility. The game was applied in ma class sexton year of a municipal school and with the participation of 12 students. A pre-test on the subject environmental education was applied after the game use, followed by a post-test. The results show theme learning evidence solely to the use of game. After the experiment, students responded of a perception test on the use of gaming environment.

keywords: Educational technology, Student activities, Student experiments. 


\section{INTRODUÇÃO}

Um software educativo é todo o sistema que tem como objetivo a melhora do processo de ensino e aprendizagem de um conteúdo ou determinada temática. Segundo Mendes et al. [1], com ele é possível aumentar o crescimento intelectual do aluno, despertando a curiosidade e tornando as aulas mais dinâmicas e interessantes.

$\mathrm{Na}$ área da educação ambiental, apesar de vários softwares educativos disponibilizados, como o Coleta Seletiva [2], Natureza Brincalhona [3], entre outros, que abordam, cada um uma temática específica, ou um único recurso natural. Neste caso, o professor deve trabalhar com vários softwares, o que demanda tempo e muitas vezes custos para encontrar o material necessário.

Na busca por materiais que abordassem a temática da educação ambiental com vários recursos, encontrouse o software "O Desafio de Gaia" [4], [5]. Este software trabalha, através de mini-games, em um único ambiente os recursos água, energia, resíduos e mobilidade. Este ambiente de ensino e aprendizagem para educação ambiental é distribuído em um projeto denominado AES-Sul na Comunidade (Projeto que visa promover ações de consciência do uso da energia e da água além de temas como mobilidade urbana e lixo) [6], onde professores e alunos são mobilizados para o uso consciente dos recursos ambientais e da preservação do meio ambiente.

Após testes com o software por parte de professores, este foi selecionado para ser utilizado nas aulas de educação ambiental, com uma turma do sexto ano de uma escola do interior do Rio Grande do Sul - Brasil. Este artigo apresenta a validação de uso realizada junto a esta turma. Para tanto, os alunos realizaram um pré-teste buscando descobrir os conhecimentos prévios sobre o meio ambiente e após o jogo um pósteste para ver a evolução do conhecimento através do jogo. Apesar de uma turma pequena, composta por
12 alunos (uma escola da zona rural e muito pequena), os resultados apresentaram indícios de que houve uma aprendizagem significativa tão somente com o uso do ambiente de jogo.

Este artigo está dividido da seguinte forma: na seção dois é discutido o assunto educação ambiental, sua trajetória no mundo e no Brasil. Na seção três é apresentado o jogo Desafio de Gaia, suas características e recursos abordados em cada minigame. A seção quatro demonstra a metodologia aplicada no experimento, seguida dos resultrados que são discutidos e das considerações finais.

\section{EDUCAÇÃO AMBIENTAL}

A educação ambiental iniciou sua caminhada entre os anos 50 e 60, pois algumas pessoas mostravam-se preocupadas com o avanço da indiferença da população frente aos problemas ambientais. No ano de 1962, a escritora e jornalista norte - americana Rachel Louise Canson, publicou o livro "Primavera Silenciosa", que despertava para as ações humanas sobre o meio ambiente. A partir de então, governantes e estudiosos passaram a observar a natureza e o planeta com maior atenção.

Nos anos seguintes, vários acontecimentos históricos que envolvem a educação ambiental ocorreram ao redor do mundo, todos direcionados para a preservação, consciência, sustentabilidade e cuidado com o meio ambiente. No Brasil, este movimento também ganhou destaque, com a publicação de diversas leis e pareceres favoráveis a conservação do planeta.

No ano de 1985, o Parecer 819/85 do MEC, propunha a inclusão da educação ambiental no processo de formação no ensino de 10 e 2 o graus integrados a todas as áreas do conhecimento, tendo como objetivo, a formação ecológica e consciente do futuro cidadão. Mais tarde, no ano de 1991, a Portaria 
678/91 do MEC, definiu que o sistema de ensino deveria abordar a educação ambiental, contemplando os currículos de todos os níveis de escolaridade [7]. Por fim, foi promulgada a Lei № 9.795 de 27 de abril de 1999 [8], que instituiu a Política Nacional de Educação Ambiental, onde aborda a educação ambiental em si, a política nacional que rege este assunto, o tema no ensino formal desde a educação infantil até a educação superior, passando por todos os níveis de escolaridade da educação ambiental não formal e a execução da política da educação ambiental.

Diante da presente situação ambiental do planeta, a educação e a preservação ambiental vem ganhando um maior destaque na sociedade, em decorrência da importância de se resguardar o ambiente, pensando não apenas em nossa geração, mas principalmente nas futuras gerações, tendo a consciência de que os recursos naturais devem ser utilizados de forma responsável, sem desperdícios. Assim, a educação ambiental tem como propósito que o ser humano passe a viver e conviver de forma harmoniosa e consciente com a natureza, refletindo sobre suas atitudes e valores para com a sociedade e o meio ambiente.

Neste contexto, a finalidade das questões ambientais é transformar o pensamento de que os recursos naturais são inacabáveis, e procurar modificar as reflexões sociais acerca da importância do planeta. Sendo assim, nada melhor do que iniciar esta conscientização pelas crianças, onde é possível abordar valores ambientais desde pequenos, para que quando adultos tenham atitudes responsáveis e sustentáveis.

A educação ambiental é fonte de conhecimento e aprendizagens sobre o meio ambiente, através da qual é possível relacionar-se de forma harmoniosa com a natureza. Assim, a segunda finalidade da educação ambiental, segundo Dias [9], é "proporcionar a todas as pessoas a possibilidade de adquirir os conhecimentos, o sentido dos valores, o interesse e as atitudes necessárias para protegerem e melhorarem o ambiente".

Ainda de acordo com o mesmo autor [9], "o Brasil é o único país da América Latina que tem uma política nacional específica para a Educação Ambiental". Desta forma, é de extrema importância pensar em recursos para abordar a educação ambiental no âmbito educacional, e iniciando estes aprendizados ainda na educação infantil, para que nossas crianças aprendam desde pequenas a valorizar, respeitar e preservar as inúmeras riquezas de nosso planeta. Além disso, aprender a utilizar os recursos oriundos da natureza de forma cuidadosa.

Devemos ter claro que a educação ambiental e a sustentabilidade não abordam apenas questões que envolvem diretamente o ambiente, mas também, relações que estão interligadas com a minha pessoa, com o outro e, consequentemente, com a natureza. Logo, Gadotti [10] cita que diante do possível extermínio do planeta, surgem alternativas numa cultura da paz e da sustentabilidade. Sustentabilidade não tem a ver apenas com a biologia, a economia e a ecologia. Sustentabilidade tem a ver com a relação que mantemos com nós mesmos, com os outros e com a natureza.

Desta maneira, tanto a escola como a família e a sociedade, tem a função de formar indivíduos críticos, pensantes e atuantes, para que na idade adulta, não se tornem indiferentes diante das questões ambientais e sociais.

\section{O JOGO DESAFIO DE GAIA}

O jogo "Desafio de Gaia" [4] e [5] tem como objetivo abordar, de forma lúdica e didática, o tema educação ambiental e meio ambiente, buscando conscientizar os educandos da importância da preservação do meio ambiente. Com a premissa de criar uma cidade 
sustentável, o jogador é apresentado à personagem Gaia e aos seus diferentes jogos, sendo transportado para dentro de uma pequena cidade.

O jogador é encarregado de gerenciar os recursos presentes no jogo, e assim contribuir para o crescimento sustentável da cidade. Na parte inferior existem quatro recursos: Água, Energia, Resíduos e Mobilidade. Cada recurso possui 3 mini-jogos diferentes, com objetivos e regras próprios. Nesta tela, o jogador pode escolher livremente qual minijogo quer jogar, não há a necessidade de seguir uma ordem prévia. A barra de evolução também está presente neste menu, sendo vista na parte superior da tela. Ainda na seleção de jogo existe uma estrela posicionada no canto inferior esquerdo, indicando o valor de pontuação necessário para melhorar o recurso.

A medida que o jogador acumula pontos, pode evoluir aquele recurso em específico. A primeira evolução ocorre quando chegar aos mil pontos e a segunda aos cinco mil pontos. Na Fig. 1 é possível perceber a evolução do recurso Mobilidade, quando na sua terceira fase, obtêm três estrelas no canto inferior esquerdo e a alternativa de melhoria na cidade chega ao seu máximo. Sempre quando se alcança este nível, ganha-se em crescimento de forma sustentável e respeitando o meio ambiente.

A maioria das fases possui um sistema de pontuação e também o desafio tempo como aumento de dificuldade. Este desafio coloca para o jogador o fator de escolha rápida. De modo geral, cada mini-jogo possui uma regra básica a ser cumprida pelo jogador. No início o jogador possui um tempo para realizar esta ação, a medida que ele vai acertando e o tempo vai aumentando, o grau de dificuldade aumenta. O caráter educativo dos jogos estimula as escolhas do jogador e não simplesmente penaliza por uma escolha errada. Além disso, sempre ao final de um mini-jogo, é disponibilizada uma dica para o problema apresentado. A seguir são apresentados os recursos disponibilizados no jogo.

O jogo Desafio de Gaia busca conscientizar de forma lúdica e divertida o gerenciamento de recursos como água, energia, resíduos e mobilidade. Além de cada um desses jogos possuírem níveis, a própria cidade pode evoluir. O formato do jogo é não-linear, possibilitando ao jogador escolher qual recurso prefere e dentro dele qual jogo quer experimentar primeiro.

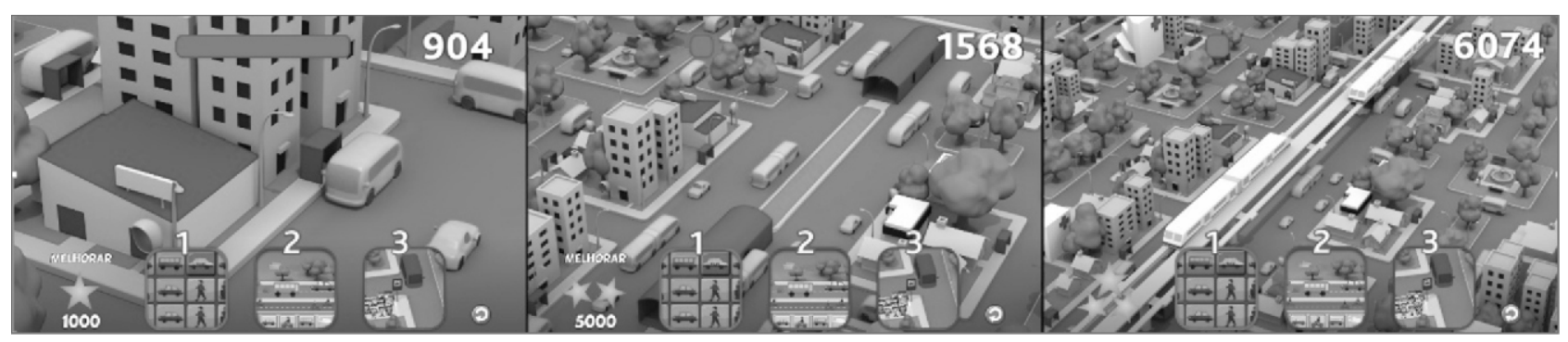

Figura 1. Crescimento da cidade sustentável. À esquerda a fase incial, com uma cidade pequena e facilmente administrável. Ao centro, a cidade com tamanho médio com um nível mediano de dificuldade e à direita, uma cidade grande, que consome muitos recursos 


\subsection{Recursoágua}

O primeiro mini-jogo, do recurso água, consiste em o jogador cuidar de um rio que está sofrendo com a poluição. Ele deve separar o que é lixo dos peixes, que devem continuar o seu caminho. Cada vez que o jogador não consegue eliminar o lixo e ultrapassar a barreira entre o rio, ele perde uma vida. Quanto mais tempo passa, mais rápido e mais objetos e peixes são colocados em jogo. O jogo é encerrado quando o jogador perder três vidas.

No segundo mini-jogo, da água, o jogador deve cuidar tanto da parte de cima da tela quanto da de baixo. $\mathrm{Na}$ parte superior da tela o jogador deve manter o fluxo dos canos roxos em sequência, possibilitando a passagem natural da água. Para isso deve dar um clique no cano que está errado até ele ficar na forma correta. Na parte inferior, a preocupação é a de manter as torneiras e chuveiros abertos quando são utilizados por pessoas, caso contrário, devem ser fechados, clicando no registro correspondente.

No último jogo do recurso água, o jogador possui o tempo de um dia, mostrado na barra que vai do sol até a lua, para gerenciar a quantidade de água para um determinado número de pessoas para os itens de consumo pessoal, limpeza doméstica, higiene pessoal e preparação de alimentos. O jogador fica responsável pelo equilíbrio da água a ser usada. Quando o objetivo é atingido, no final do dia, o jogo altera o número de pessoas e o tempo dia/noite fica mais rápido.

\subsection{Recurso energia}

O primeiro mini-jogo do recurso energia possui como característica a economia da energia elétrica em casa. O jogador deve apagar as luzes que estão acessas quando nenhuma pessoa estiver no quarto, quando há alguém, ele deve ascender a luz. O tempo e dificuldade estão conectados também neste jogo.

O segundo jogo sobre Energia é um gerenciador de recursos, onde o jogador deve abastecer um tanque com energia gerada pelas usinas e a partir disso passar para as casas. No terceiro jogo, a personagem Gaia vai passando por diversos cômodos da sua casa, por onde ela passa ascende as luzes e o jogador deve clicar em cima da lâmpada quando ela não estiver mais presente naquele local para desligar e poupar energia. A Fig. 2 apresenta exemplos de mini-jogos do recurso energia.

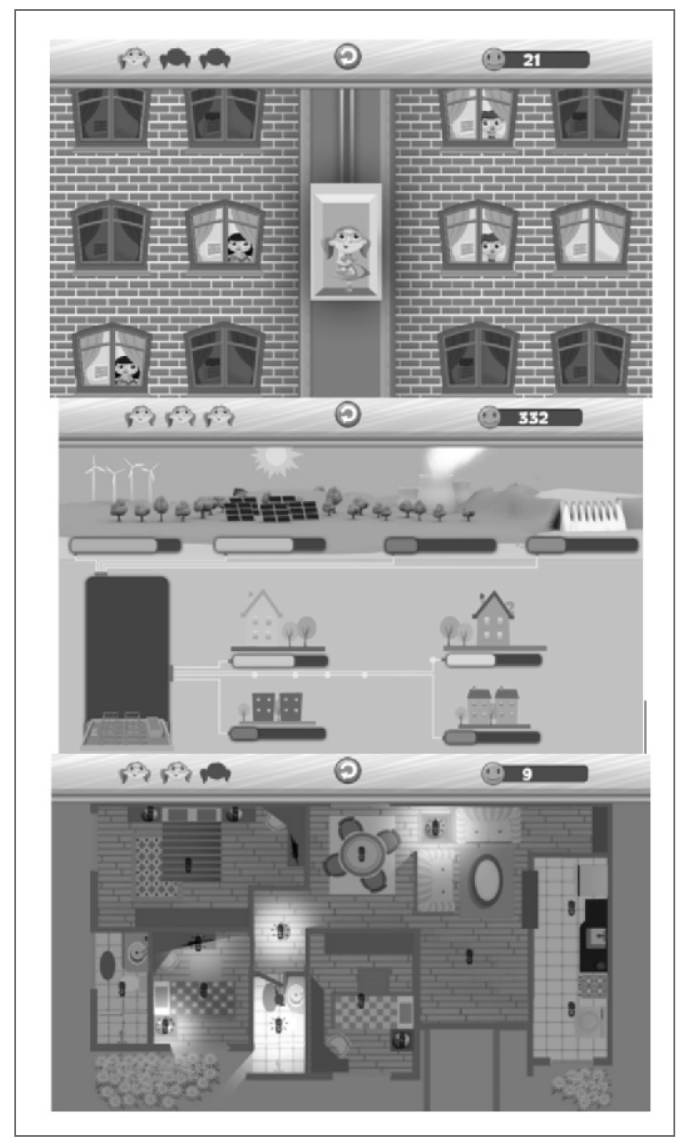

Figura 2. Exemplo dos mini-jogos do recurso energia. Acima, à esquerda, energia elétrica em casa, acima, à direita, energia gerada por usinas e abaixo, economia de energia.

\subsection{Recurso resíduos}

O recurso de resíduos tem como objetivo ensinar sobre a separação do lixo, suas fases demonstram essa atividade em diversos locais. No primeiro mini-jogo 
(Fig. 3 a esquerda), o jogador deve deixar cair na composteira o que é lixo orgânico e o que não for, deve cortar para não chegar ao destino.

O próximo mini-jogo é sobre a separação do lixo em seis tipos diferentes. O jogador conta com três tipos de latas na lateral esquerda e mais três na lateral direita da tela (Figura 3 central). Os tipos da esquerda são: plástico, papel e orgânico e na direita: vidro, metal e não orgânico. No centro da tela são apresentadas três esteiras onde os objetos vão chegando, cada objeto conta com a cor da sua lixeira no seu contorno para auxiliar o jogador na sua escolha.

No terceiro mini-jogo sobre resíduos, o jogador é incumbido de criar através de objetos recicláveis. No jogo é apresentado o objeto a ser construído, em seguida somente é visto a silhueta e em um determinado tempo o jogador deve escolher os itens que compõem o objeto.

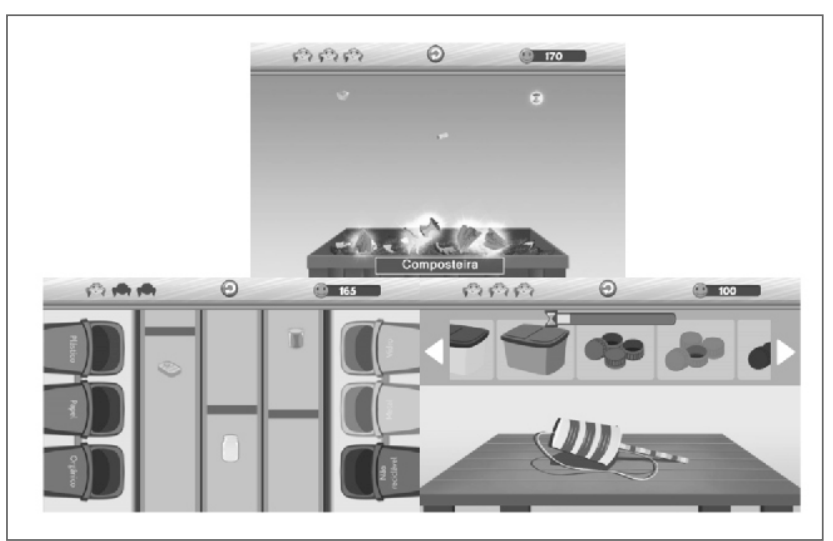

Figura 3. Exemplo dos mini-jogos do recurso resíduos. Acima, à esquerda, composteira, acima, à direita, reciclagem.

\subsection{Recurso mobilidade}

O recurso Mobilidade possui como foco a conscientização na forma de se locomover na cidade de maneira sustentável. No primeiro jogo, o jogador deve juntar 3 peças para que elas sumam e novas surjam. Quando o tempo acaba, o jogo termina.
No segundo jogo, com o tema mobilidade, o jogador possui uma meta de pessoas para transportar cuidando da poluição. Para isso, ele pode escolher quais veículos usar para transportar as pessoas, sabendo o quanto ele polui. Quando a poluição toma conta da tela ou o número de pessoas a ser transportada dentro do tempo não acontece, o jogador perde uma vida.

O terceiro mini-jogo da mobilidade consiste em utilizar a linha de ônibus correta para recolher os passageiros no ponto de ônibus. Cada vez que um novo passageiro chega, ele tem um tempo de espera a ser respeitado e o ônibus não pode atrasar mais que este tempo. A quantidade de linhas de ônibus com destinos diferentes pode chegar a quatro. A Fig. 4 apresenta telas do jogo.

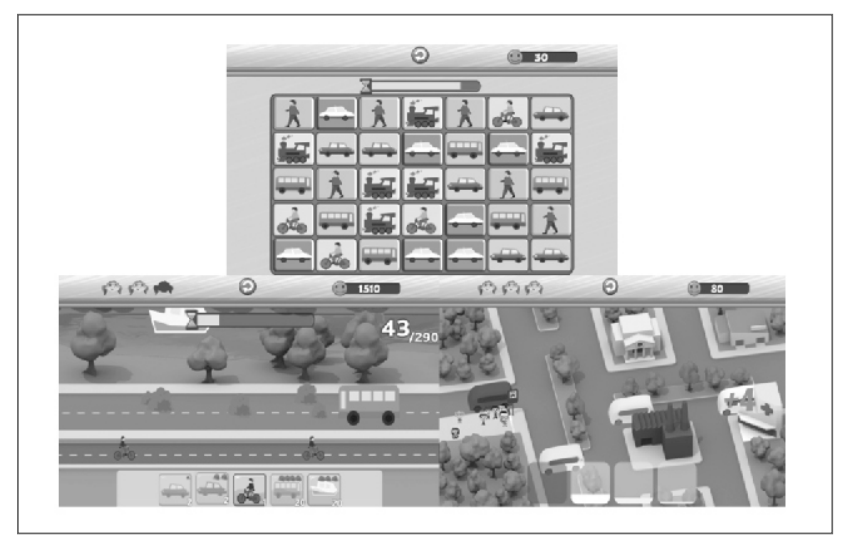

Figura 4. Exemplo dos mini-jogos do recurso mobilidade. Acima, à esquerda, reunindo peças, acima, à direita, gerencamento de poluição com os transportes e abaixo o uso correto dos ônibus.

\section{MÉTODOS}

Nesta seção será descrita a população onde se aplicou o jogo, o método de investigação e instrumentos utilizados para medir seu impacto. Se contou com a participação de uma turma de estudantes do sexto ano da Escola Municipal de Ensino Fundamental Nereu Ramos, situada na cidade de Lindolfo Collor, RSBrasil. 
A escola, situada na zona rural, conta com aproximadamente 110 alunos, de Jardim ao 9o. ano. Fundada em 1969, a escola atende a famílias que vivem basicamente da produção de hortifrutigranjeiros. No total, na série trabalhada, os estudantes tem em média entre onze e doze anos e são divididos em seis do sexo feminino e seis do sexo masculino.

O método de investigação utilizado seguiu um desenho quase-experimental onde a população foi dividida em dois grupos de seis alunos. Enquanto um grupo jogava, o outro realizava uma atividade que não tinha a ver com o conteúdo. Chamamos de quaseexperimental porque a seleção dos estudantes dentro dos grupos não se realizou de maneira aleatória, mas por conveniência da realidade da escola.

Os grupos responderam a um pré-teste de conhecimentos prévios sobre o conteúdo abordado na disciplina, tendo como tema os recursos: água, resíduos, energia e mobilidade. Não foram apresentadas explicações sobre o conteúdo antes de aplicar o pré-teste. Uma semana após o pré-teste, realizou-se a intervenção com o jogo e aplicou-se um pós-teste, análogo ao pré-teste, ou seja, não exatamente iguais, mas com os mesmos conteúdos. Os dois testes contavam com seis questões cada.

Foi aplicado, após a intervenção, um questionário de percepção do experimento, composta por 11 questões (Apêndice). Cada pergunta deveria ser respondida em uma escala do tipo Likert de um a cinco, onde um era a classificação mais baixa e cinco a mais alta. Também havia espaço para comentários dos respondentes.

\section{RESULTADOS E ANÁLISES}

Os resultados finais do pré-teste e pós-teste de rendimento, realizado para auferir o conhecimento do grupo sobre as temáticas envolvendo educação ambiental antes e depois dos alunos jogarem são apresentados na Tabela 1. Na sequência, a Fig. 5 apresenta o gráfico com a evolução da pontuação dos alunos nos testes.

\begin{tabular}{|l|c|c|}
\hline \multirow{2}{*}{ Nome } & \multicolumn{2}{|c|}{ Pontuação } \\
\cline { 2 - 3 } & Pré-teste & Pós-teste \\
\hline Aluno 1 & 3,0 & 4,5 \\
\hline Aluno 2 & 5,0 & 5,5 \\
\hline Aluno 3 & 3,0 & 4,5 \\
\hline Aluno 4 & 3,5 & 4,5 \\
\hline Aluno 5 & 5,0 & 6,0 \\
\hline Aluno 6 & 4,0 & 5,0 \\
\hline Aluno 7 & 4,5 & 6,0 \\
\hline Aluno 8 & 5,0 & 5,0 \\
\hline Aluno 9 & 5,5 & 6,0 \\
\hline Aluno 10 & 5,5 & 6,0 \\
\hline Aluno 11 & 5,0 & 5,5 \\
\hline Aluno 12 & 5,0 & 5,5 \\
\hline Média & 4,5 & 5,3 \\
\hline
\end{tabular}

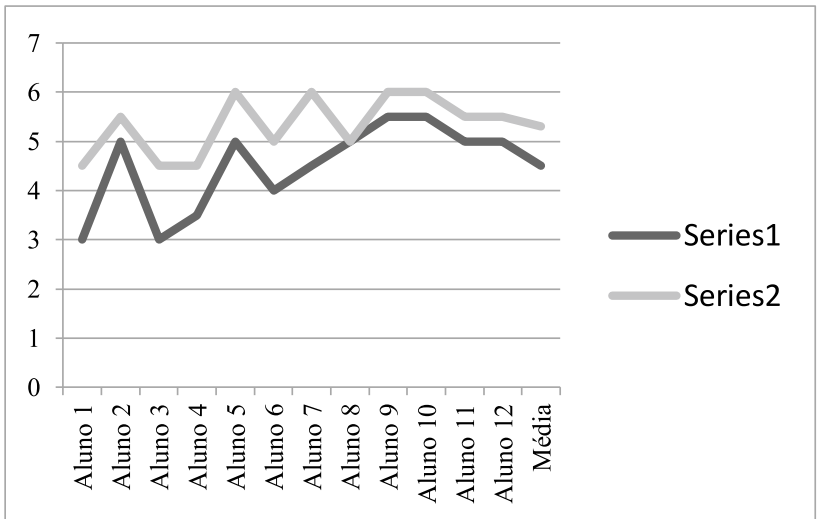

Figura 5. Gráfico demonstrativo do número de acertos por aluno no pré-teste (linha azul) e pós-teste (linha vermelha).

Verificando os resultados obtidos no pré-teste, a média geral dos alunos foi de 4,5, enquanto no pósteste foi de 5,33, sendo o máximo possível 6,0. Apenas um aluno não melhorou a nota no pós-teste em relação ao pré-teste, mantendo-a igual $(5,0)$. Cinco 
alunos no pré-teste tiveram nota igual a 4,0 ou inferior, enquanto que no pós-teste, a menor nota foi de 4,5, com quatro ocorrências. No pré-teste, nenhum aluno acertou todas as questões, sendo que no pós-teste, quatro alunos acertaram 100\% das questões.

De uma forma geral, pode-se perceber que os alunos apresentaram uma melhora significativa em seus conhecimentos sobre o uso de recursos naturais. Se levarmos em consideração que não houve explicação alguma por parte da professora em relação ao conteúdo, podemos auferir que o conteúdo foi aprendido a partir do ambiente de jogo.

No questionário aplicado após o experimento buscávamos saber sobre como foi a experiência para os alunos. As questões respondidas pelos alunos são apresentadas na sequência.

Quando questionados se estes se sentiam interessados nas aulas de ciências, dos 12 alunos, quatro responderam sentir-se razoavelmente interessados, quatro indicaram estar um pouco interessados e quatro muito. Sobre as aulas de ciências serem agradáveis, dois indicaram ser razoavelmente, seis agradáveis e quatro muito agradáveis.

Sobre o método aplicado pela professora antes do jogo, três indicaram ser razoável, dois bom e sete muito bom. Perguntados se indicariam esse método a outras disciplinas, um indicou que não e os demais que sim.

Foi perguntado se na opinião dos alunos o jogo proporcionou aprendizado. Um aluno indicou que não, os demais indicaram que sim, proporcionou aprendizado. Uma aluna destacou que antes de jogar, por exemplo, não sabia o que era uma composteira e que descobriu isso jogando.

Foi questionado se a forma de apresentação dos conteúdos no jogo era agradável, e um aluno indicou que não e os demais indicaram positivamente. Quando perguntado se os alunos continuariam jogando o Desafio de Gaia em casa, chama a atenção que onze alunos responderam positivamente.

Em paticamente todos os quesitos, um aluno respondeu negativamente ao experimento e fomos investirgar o porque da situação. É um aluno que apresenta TDAH (Transtorno de Déficit de Atenção e Hiparatividade). Analisamos como se deu sua performance no jogo e descobrimos que este foi o aluno que mais jogou, além de ser o que mais pontuou no jogo. Questionado sobre sua opinião, o mesmo não soube responder porque avaliou de forma negativa todas as opções.

\section{CONSIDERAÇÕES FINAIS}

Diante da atual situação ambiental, é preciso refletir sobre, como, nós professores, podemos interfererir nas ações de nossos alunos. Devemos pensar em formar cidadãos mais conscientes e responsáveis frente as questões ambientais pelas quais nosso planeta esta passando.

Nosso país possui uma imensa legislação que aborda a temática da Educação Ambiental. Um grande suporte, para que educadores abordem este assunto com seus educandos, desde a Educação Infantil até o Ensino Superior. O objetivo é proporcionar um contato maior com os recursos disponíveis na natureza e aprender a utiliza-los de forma consciente e responsável, pois temos que ter a ciência de que a disponibilidade de matéria prima é finita e em muitos casos não renovável.

A parte inicial da atividade tinha o propósito de investigar os conhecimentos prévios dos alunos, como intuito de observar e analizar os conhecimentos que eles já tinham sobre o tema. Posteriormente, aplicouse o jogo Desafio de Gaia. Neste momento foi possível 


\section{. . F.'Ingenierías}

observer que alguns alunos já faziam relações com as questões que haviam sido trabalhadas no pré-teste. Por fim, o pós-teste nos mostrou a aquisição de conhecimentos acerca do assunto por parte dos alunos.

Refletindo sobre a atividade realizada com estes alunos, foi possível observar e identificar que a utilização de jogos didáticos e pedagógicos mostram uma maior absorção e interesse, por parte dos alunos, em relação aos temas em estudo.

Esta atividade possibilitou que os educandos pudessem aprender sobre um tema relevante, e que com suas novas aprendizagens possam colocar em prática, o que aprenderam, em suas atividade diárias na escola, nas suas casas e na sociedade.

Por fim, é imporatnte salientar que cabe ao professor inicialmente analisar os ambientes a ser disponibilizados aos alunos, de forma que atendam as reais necessidades da temática proposta. Neste caso, o professor atua como mediador do processo, buscando materiais e conduzindo seus alunos no caminho de aprender a aprender.

Acknowledgment: Agradecemos a Escola Municipal de Ensino Fundamental Nereu Ramos por ter permitido realizer os experimentos durante as aulas de educação ambiental e aos alunos que participaram das atividades.

\section{REFERENCIAS}

Aes Sul. Site da empresa. Disponível em: <https://www.aessul.com.br>. Acesso em março de 2016.

Aes Sul. Site da empresa. Disponível em: $<$ https://www.aessul.com.br $>$.Acesso em junho de 2015.

C. V. de A. Carvalho, J. V. Carvalho, W. C. R. (2009). Software COLETASELETIVA: Um sistema computacional educativo para conscientização da importância da coleta seletiva. Revista Práxis, 1(2).

Dias, Genebaldo F. (2004). Educação Ambiental: princípios e práticas. São Paulo: Gaia.

Gadotti, Moacir (2012). Educar para a SustentabilidadeSão Paulo: Ed,L.

Lei Federal no 9.795, de 27 de abril de 1999. Dispõe sobre a Educação Ambiental, institui a Política Nacional de Educação Ambiental e dá Outras Providências. Disponível e m: < http://www.planalto.gov.br/ccivil_03/leis//9795.htm >. Acesso em: 29 jul.2015.

Mendes, J. L. De S.; Carvalho, C. V. A.; Carva- Lho, J. V. (2007). CONSTRUFIG3D: Uma Ferramenta Computacional para apoio ao ensino da Geometria Plana e Espacial. RENOTE - Revista Novas Tecnologias na Educação, 5(1), 1-10. Disponível em http://www.cinted.ufrgs.br/renote/jul2007/index.ht ml. Acessado em abril de 2016.

Ministério da Educação. Um pouco da História da Educação Ambiental. Disponível em:<http:// http://portal.mec.gov.br/secad/arquivos/pdf/educac aoambiental/historia.pdf>. Acesso em: 19 jul. 2015.

Natureza Brincalhona (2009). Fundada por Dina Silva, Mônica Silva e Vítor Rosário. Disponível em: 
http://www.natureza-brincalhona.pt/index.html. Acesso em: abril de 2009.

Silva, A. S., Bulhoes, T. M. y Bez, M. R. (2015). Jogos que compõem o Desafio de Gaia. In: CAVA 2015- VII Congresso Internacional de Ambientes Virtuais de Aprendizagem Adaptativos e Acessivos, 2015, Novo Hamburgo. Anais do VII Congresso Internacional de Ambientes Virtuais de Aprendizagem Adaptativos e Acessivos. Novo Hamburgo: Fundação Escola Técnica Liberato Salzano Vieira da Cunha, 2015. v. 1. p. 690695.

\section{APÊNDICES}

\section{TESTE DE PERCEPÇÃO \\ ESCOLA MUNICIPAL DE ENSINO FUNDAMENTAL NEREU \\ RAMOS \\ PROJETO DESAFIO DE GAIA}

Nome do aluno:

Por favor, responda as seguintes perguntas de forma honesta. Não te preocupes, as respostas não serão avaliadas. A avaliação vai de 1 a 5 , sendo:

1 = Muito ruim, 2 = Ruim, 3 = Médio, 4 = Bom e 5 = Muito bom.

1) Em geral, o quanto tu te sente interessado na aula de Ciências?

\begin{tabular}{|l|l|l|l|l|}
\hline 1 & 2 & 3 & 4 & 5 \\
\hline & & & & \\
\hline
\end{tabular}

2) O quanto as aulas de Ciências te parecem agradáveis?

\begin{tabular}{|l|l|l|l|l|}
\hline 1 & 2 & 3 & 4 & 5 \\
\hline & & & & \\
\hline
\end{tabular}

3) Como te parece o método que a professora usava em aula até o jogo?

\begin{tabular}{|l|l|l|l|l|}
\hline 1 & 2 & 3 & 4 & 5 \\
\hline & & & & \\
\hline
\end{tabular}

4) Tu sugeriria que o mesmo método das aulas de ciência fosse aplicado em outras aulas?

\begin{tabular}{|l|l|l|l|l|}
\hline 1 & 2 & 3 & 4 & 5 \\
\hline & & & & \\
\hline
\end{tabular}

5) Já participastes de outras experiências de aprendizado de conteúdo através de jogos?

$($ ) $\operatorname{sim}($ ) Não Quais?

6) O uso do jogo, na sua opinião, proporcionou aprendizado do conteúdo de ciências?

\begin{tabular}{|l|l|l|l|l|}
\hline 1 & 2 & 3 & 4 & 5 \\
\hline & & & & \\
\hline
\end{tabular}

7) A forma como os conteúdos são apresentados no jogo é agradável

\begin{tabular}{|l|l|l|l|l|}
\hline 1 & 2 & 3 & 4 & 5 \\
\hline & & & & \\
\hline
\end{tabular}

8) É melhor aprender tendo primeiro o conteúdo e depois o jogo ou o contrário?

( ) Primeiro o jogo, depois o conteúdo

( ) Primeiro o conteúdo, depois o jogo

9) Você gostou da experiência de jogar o Desafio de Gaia?

() $\operatorname{sim} \quad($ ) Não

10) Você continuaria jogando Desafio de Gaia em casa?

( ) $\operatorname{sim}($ ) Não

11) Você costuma jogar no computador?

( ) $\operatorname{sim}($ ) Não

Quantas vezes por semana?

Quais jogos? 